\title{
The association between symptoms and exposure is stronger in dropouts than in non-dropouts among employees in Norwegian smelters: a five-year follow-up study
}

\author{
Vidar Søyseth • Helle Laier Johnsen • \\ Merete Drevvatne Bugge $\cdot$ Johny Kongerud
}

Received: 7 October 2010/Accepted: 10 March 2011/Published online: 29 March 2011

(c) The Author(s) 2011. This article is published with open access at Springerlink.com

\begin{abstract}
Purpose We have investigated the association between respiratory symptoms and dust exposure among employees in 18 Norwegian smelters using a longitudinal design.

Methods All employees $(N=3,084)$ were examined annually for 5 years $(12,996$ health examinations). At each examination, the subjects reported if they had respiratory symptoms, coded as 1 (yes) or 0 (no), on a respiratory questionnaire. Symptom score was constructed as the sum of symptoms (0-5). Full-time workers in the production line were classified as line operators; subjects never exposed in the production line were regarded as nonexposed. The remaining individuals were classified as nonline operators. A job-exposure matrix regarding dust exposure was also available. Analyses of repeated measurements were performed using generalised linear mixed model with log-link (Poisson regression). Adjustments were made for overdispersion.

Results The mean age at inclusion was 39.0 years, and $89 \%$ were men. The median dust exposure in tertiles 1-3 was $0.19,1.76$ and $3.47 \mathrm{mg} / \mathrm{m}^{3}$. The longitudinal analyses showed that the association between symptoms-score ratio
\end{abstract}

\footnotetext{
V. Søyseth $(\bowtie) \cdot$ H. L. Johnsen

Department of Medicine, Faculty Division Akershus University Hospital, University of Oslo, 1478 Lørenskog, Norway

e-mail: vidar.soyseth@medisin.uio.no

V. Søyseth · H. L. Johnsen · J. Kongerud

Faculty of Medicine, University of Oslo, Oslo, Norway

M. D. Bugge

National Institute of Occupational Health, Oslo, Norway

J. Kongerud

Department of Respiratory Medicine, Faculty Division

Rikshospitalet, University of Oslo, Oslo, Norway
}

(SSR) and job category was significantly stronger in dropouts compared with non-dropouts $(p=0.01)$. Among the dropouts, SSR was 1.61 (95\% confidence interval: $1.27-2.05)$ and 1.39 (1.09-1.77) in line operators and nonline operators compared with non-exposed employees, respectively. The corresponding SSR for subjects who completed the study was $1.13(1.01-1.27)$ and 1.12 (1.00-1.26), respectively. Similarly, among the dropouts, the SSR between the second and the first tertile was 1.28 (1.05-1.55) and $1.37(1.13-1.66)$ between the third tertile and the first tertile.

Conclusions Line operators had more respiratory symptoms than non-exposed employees. This effect was significantly stronger in dropouts than in those who continued their jobs, indicating that there is a selection of subjects without respiratory symptoms in this industry.

Keywords Respiratory symptoms - Occupational dust exposure · Dropout · Longitudinal study $\cdot$ Poisson regression

\section{Introduction}

The Norwegian smelting industry produces ferrosilicon alloys (FeSi), silicon metal (Si-metal), ferromanganese (FeMn), silicon manganese ( $\mathrm{SiMn})$, ferrochromium (FeCr), silicon carbide ( $\mathrm{SiC})$, titanium (II) oxide $\left(\mathrm{TiO}_{2}\right)$ and calcium carbide $\left(\mathrm{CaC}_{2}\right)$. During the production, several air pollutants are emitted to the workplace environment, foremost particulates and gases that are potentially harmful to the airways (Foreland et al. 2008; Johnsen et al. 2008a, $\mathrm{b}, \mathrm{c})$. In a cross-sectional study of employees in this industry, we found that subjects who worked full time in the production line (line operators) had lower lung function 
expressed as forced expiratory volume in one second $\left(\mathrm{FEV}_{1}\right)$ as well as forced vital capacity (FVC), compared with non-exposed workers (Johnsen et al. 2008b). Moreover, longitudinal analyses showed that they also had steeper annual decline in $\mathrm{FEV}_{1}$ compared with those who were non-exposed (Soyseth et al. 2007). The rate of annual change decreased with increasing dust exposure in smelters producing FeSi, Si-metal, FeMn, SiMn and FeCr (Johnsen et al.). The prevalence of airflow limitation during 5-year follow-up was higher in line operators compared with nonexposed individuals (Soyseth et al. 2011). Moreover, analyses of baseline showed that employees working full time in the production line in 24 Norwegian smelters had a significantly higher prevalence of cough and phlegm than non-exposed workers (Johnsen et al. 2008c). Subjects reporting previous exposure to fumes, dust or irritating gases had a significantly higher prevalence of dyspnoea, cough without colds, daily cough more than 3 months during the last year (chronic bronchitis), and phlegm than employees without such exposure.

Several epidemiologic studies have indicated that mucus hypersecretion, cough, and breathlessness are associated with increased mortality (Krzyzanowski and Wysocki 1986; Lange et al. 1990; Rosengren and Wilhelmsen 1998; Vestbo et al. 1989). Different respiratory symptoms are, however, not specific regarding the diagnosis of lung diseases. In epidemiologic settings, the impact of respiratory symptoms on health can be investigated using a score expressed as the sum of symptoms.

In a 30-year follow-up of a large cohort of the general population, we found a dose-response relationship between symptom score (i.e. the sum of confirmative answers to 11 respiratory symptoms) and all cause mortality, cardiovascular mortality, as well as mortality of obstructive lung disease (Frostad et al. 2006a, b, 2007). Accordingly, we have constructed a symptom score as the sum of confirmative answers to five respiratory questions among employees in Norwegian smelters.

The aim of the study was to investigate the association between respiratory symptoms expressed as symptom score and occupational exposure using longitudinal analyses.

\section{Methods}

All employees $(n=3,924)$ aged $20-55$ years in 24 Norwegian smelters and related workplaces were invited to participate in a longitudinal respiratory study. The study was conducted between 1996 and 2003. They were followed annually (16,570 observations) with spirometry and a respiratory questionnaire (Kongerud et al. 1989); details are explained elsewhere (Johnsen et al. 2008c; Soyseth et al. 2007). In smelters producing FeSi, Si-metal, FeMn, $\mathrm{SiMn}, \mathrm{FeCr}$ or $\mathrm{SiC}$, measures of dust exposure using personal samplers were available. Therefore, the current study was limited to these smelters $(n=18)$. Accordingly, the number of employees was 3,084 and they underwent 12,996 examinations. The age distribution is shown in Table 1.

On the respiratory questionnaire, the subjects were asked to report their symptoms during the last year. Symptom score was constructed as the sum of a confirmative answer (score $=1$ if 'yes', 0 if 'no', otherwise 'missing') to the following questions: dyspnoea, wheezing, cough without a cold, daily cough for 3 months or longer and phlegm. Hence, in each subject, the symptom score was an integer between 0 and 5 . The symptom score could vary within each individual during the follow-up. In case of

Table 1 The prevalence of respiratory symptoms during the follow-up

\begin{tabular}{|c|c|c|c|c|c|c|}
\hline \multirow[b]{2}{*}{ Symptom, $n(\%)$} & \multicolumn{6}{|c|}{ Examination no. } \\
\hline & 1 & 2 & 3 & 4 & 5 & 6 \\
\hline Dyspnoea & $708(23.0)$ & $605(21.4)$ & $475(19.3)$ & $398(19.3)$ & $301(18.2)$ & $151(16.8)$ \\
\hline Unknown & $47(1.5)$ & $74(2.6)$ & $76(3.1)$ & $69(3.3)$ & $15(0.9)$ & $4(0.4)$ \\
\hline Wheezing & $598(19.4)$ & $500(17.7)$ & $443(18.0)$ & $341(16.5)$ & $273(16.5)$ & $142(15.8)$ \\
\hline Unknown & $55(1.8)$ & $76(2.7)$ & $76(3.1)$ & $69(3.3)$ & $15(0.9)$ & $4(0.4)$ \\
\hline Cough without a cold & $772(25.0)$ & $655(23.2)$ & $488(19.9)$ & $422(20.4)$ & 308 (18.6) & $158(17.6)$ \\
\hline Unknown & $76(2.5)$ & $101(3.6)$ & $101(4.1)$ & $82(4.0)$ & $26(1.6)$ & $8(0.9)$ \\
\hline Cough $>3$ months last year & $267(8.7)$ & $271(9.6)$ & $224(9.1)$ & $181(8.8)$ & $137(8.3)$ & $66(7.3)$ \\
\hline Unknown & $82(2.7)$ & $106(3.8)$ & $103(4.2)$ & $85(4.1)$ & $29(1.8)$ & $8(0.9)$ \\
\hline Phlegm when coughing & $648(21.0)$ & $566(20.0)$ & $484(19.7)$ & $388(18.8)$ & 297 (18.0) & 168 (18.7) \\
\hline Unknown & 139 (4.5) & $144(5.1)$ & $126(5.1)$ & 97 (4.7) & $40(2.4)$ & 13 (1.5) \\
\hline \multicolumn{7}{|l|}{ Dropouts } \\
\hline $\mathrm{N}$ & 149 & 158 & 192 & 80 & 5 & 0 \\
\hline Symptom score, mean & 1.24 & 1.16 & 1.04 & 0.98 & 0.95 & 0.90 \\
\hline
\end{tabular}


missing value(s), the corresponding record was excluded. In total, $1,496(12 \%)$ of the records $(n=12,996)$ were excluded from the analyses due to missing values. Allergy was considered to be present if the employee had a history of either hay fever or atopic eczema.

Information about job category and smoking habits during the previous year was obtained from the questionnaire. Occupational exposure was assessed using a qualitative job classification and a quantitative job-exposure matrix (JEM). The qualitative job classification was constructed as follows: Employees working full time in the production line during the last year were classified as line operators, whereas employees who never worked in the production line during the last year were classified as nonexposed. The remaining subjects were classified as nonline operators (Johnsen et al. 2008c). Thus, non-line operators could be regarded as part-time exposed to pollution emitted from the production.

The JEM was constructed as the geometric mean of total dust exposure in each job category in each smelter (Foreland et al. 2008; Johnsen et al. 2008a). Dust from the working atmosphere was collected by personal samplers during the study period. Each employee was allocated to the dust exposure for the corresponding job category the previous year. If an employee changed job category during the year, a time-weighted average of the geometric mean was used. These estimates indicated that the qualitative job classification differentiated well regarding individual exposure to dust. Information of job category, and thereby qualitative as well as dust exposure was updated at each examination. The distribution of dust exposure in tertiles by production is shown in Table 2 .

Subjects who had their last examination 18 months or more before the closure of the study were regarded as dropouts (Soyseth et al. 2008). The study was approved by the Regional ethics committee.

\section{Statistical analyses}

Since the outcome variable was count variable, we assumed a Poisson distribution. The data were analysed in

Table 2 Range of dust exposure (geometric mean, $\mathrm{mg} / \mathrm{m}^{3}$ ) in each tertile by production

\begin{tabular}{llll}
\hline & 1 tertile & 2 tertile & 3 tertile \\
\hline FeSi, Si-metal & $0-1.0$ & $1.1-3.1$ & $3.2-12.6$ \\
FeMn, SiMn, FeCr & $0-0.7$ & $0.8-1.8$ & $1.9-9.9$ \\
$\mathrm{SiC}$ & $0-0.7$ & $0.8-1.9$ & $2.0-11.3$ \\
\hline
\end{tabular}

$\mathrm{FeSi}$, Si-metal ferrosilicon alloys, silicon metal, FeMn ferromanganese, $\mathrm{SiMn}$ silicon manganese, $\mathrm{FeCr}$ ferrochromium, $\mathrm{SiC}$ silicon carbide two steps. First, we compared the mean and variance of symptom score in each category of the covariates. Since the outcome was a count variable, multivariable Poisson regression models were fitted to the data, both to the baseline data and the follow-up data. The latter data set was analysed using generalised linear mixed model (GLMM) (Fitzmaurice 2004). This method allows data to be unbalanced, i.e., the individuals may have unequal number of follow-up and time spacing between observations. The models were checked for overdispersion (Fitzmaurice 2004). Overdispersion may cause major concerns using Poisson regression, as it inflates type I error. In the crosssectional analysis, we tried to overcome the problem of overdispersion using a multiplicative overdispersion factor. This factor estimates an overdispersion scalar to the variance function. In the longitudinal analyses, we investigated both the effect of using random intercept and a multiplicative overdispersion parameter available in SAS PROC GLIMMIX. In all these multivariable models, we used the same covariates in the cross-sectional logistic model of the data at baseline, i.e., gender, smoking habits, job categories and previous exposure. Age was entered as the sum of age at baseline and time in study. Additionally, dropouts were included as a covariate. We included interaction terms between follow-up time and the following covariates: smoking, job category and dropouts. The fit of the generalised linear mixed model was assessed using the variance of the Pearson residual. Test for trend was performed using linear scores for tertiles. The analyses were performed using SAS 9.1 (PROC GENMOD and PROC GLIMMIX) (SAS Institute Inc. 2004. SAS OnlineDoc ${ }^{\circledR}$ 9.1.3. Cary, NC: SAS Institute Inc.).

\section{Results}

The distribution of symptoms by symptom score is shown in Table 3. Apart from symptoms of chronic bronchitis, the prevalence of each of the symptoms was approximately independent of symptom score (10-20\%). There were 584 dropouts during the study.

The mean and the variance of symptom score during the follow-up by relevant covariates are shown in Table 4 . Generally, the magnitude of the variance was twice the mean, indicating some overdispersion in the data. Except from dropouts, symptom score appeared to decline during the follow-up. However, a dose-response relationship between symptom score and smoking was indicated at each follow-up. Moreover, line operators had generally higher symptom score than non-line operators, who had higher symptom score than non-exposed employees. The standard deviation of symptom score between and within individuals was 1.2 and 0.75 , respectively. 
Table 3 The prevalence ( $\%$ in parentheses) of each symptom by symptom score

\begin{tabular}{lccccc}
\hline Symptom score & Dyspnéa & Wheezing & $\begin{array}{l}\text { Cough without } \\
\text { cold }\end{array}$ & $\begin{array}{l}\text { Cough }>3 \text { months } \\
\text { last year }\end{array}$ & $\begin{array}{l}\text { Phlegm when } \\
\text { coughing }\end{array}$ \\
\hline 0 & 0 & 0 & 0 & 0 & 0 \\
1 & $91(13.7)$ & $47(8.3)$ & $151(20.2)$ & $1(0.4)$ & $120(19.2)$ \\
2 & $167(25.2)$ & $136(24.0)$ & $177(23.7)$ & $30(11.7)$ & $130(20.8)$ \\
3 & $153(23.1)$ & $145(25.6)$ & $162(21.7)$ & $54(21.1)$ & $140(22.4)$ \\
4 & $149(22.5)$ & $136(24.0)$ & $155(20.7)$ & $69(26.9)$ & $131(21.0)$ \\
5 & $103(15.5)$ & $103(18.2)$ & $103(13.8)$ & $103(40.1)$ & $103(16.5)$ \\
Total & $663(100.0)$ & $567(100.0)$ & $748(100.0)$ & $257(100.0)$ & $624(100.0)$ \\
\hline
\end{tabular}

Table 4 Mean symptom score and the corresponding variance (in parentheses) during follow-up by relevant covariates

\begin{tabular}{|c|c|c|c|c|c|c|}
\hline \multirow[t]{2}{*}{ Covariate } & \multicolumn{6}{|c|}{ Follow-up no. } \\
\hline & Baseline & 1 & 2 & 3 & 4 & 5 \\
\hline \multicolumn{7}{|l|}{ Gender } \\
\hline Male & $1.02(2.13)$ & $0.97(2.12)$ & $0.92(2.01)$ & $0.89(2.02)$ & $0.83(1.94)$ & $0.78(1.86)$ \\
\hline Female & $0.71(1.38)$ & $0.66(1.55)$ & $0.62(1.51)$ & $0.57(1.28)$ & $0.52(1.30)$ & $0.61(1.71)$ \\
\hline \multicolumn{7}{|l|}{ Age (years) } \\
\hline $20-34$ & $0.87(1.75)$ & $0.84(1.87)$ & $0.75(1.66)$ & $0.70(1.51)$ & $0.65(1.38)$ & $0.45(1.20)$ \\
\hline $35-44$ & $1.05(2.21)$ & $1.00(2.22)$ & $0.93(2.06)$ & $0.92(2.23)$ & $0.74(1.77)$ & $0.77(1.86)$ \\
\hline $45+$ & $1.05(2.23)$ & $0.96(2.09)$ & $0.94(2.06)$ & $0.87(1.92)$ & $0.89(2.11)$ & $0.84(1.97)$ \\
\hline \multicolumn{7}{|l|}{ Smoking } \\
\hline Never smoker & $0.60(1.31)$ & $0.49(1.08)$ & $0.49(1.10)$ & $0.46(1.20)$ & $0.48(1.24)$ & $0.48(1.25)$ \\
\hline Former smoker & $0.73(1.58)$ & $0.66(1.49)$ & $0.59(1.39)$ & $0.56(1.36)$ & $0.56(1.27)$ & $0.60(1.51)$ \\
\hline \multicolumn{7}{|l|}{ Current (cig/day) } \\
\hline $1-9$ & $1.04(2.18)$ & $1.05(2.27)$ & $0.99(2.10)$ & $0.98(2.02)$ & $0.92(2.03)$ & $0.78(1.68)$ \\
\hline $10-19$ & $1.49(2.48)$ & $1.46(2.74)$ & $1.45(2.61)$ & $1.44(2.63)$ & $1.32(2.71)$ & $1.31(2.75)$ \\
\hline $20+$ & $2.22(3.36)$ & $2.31(2.57)$ & $1.81(3.08)$ & $1.65(2.70)$ & $1.72(2.94)$ & $1.55(2.76)$ \\
\hline \multicolumn{7}{|l|}{ Job categories } \\
\hline Unexposed & $0.62(1.26)$ & $0.65(1.53)$ & $0.65(1.50)$ & $0.62(1.52)$ & $0.61(1.51)$ & $0.87(2.11)$ \\
\hline Non-line operators & $0.96(2.04)$ & $0.93(2.17)$ & $0.85(1.90)$ & $0.81(1.90)$ & $0.80(2.06)$ & $0.77(1.93)$ \\
\hline Line operators & $1.10(2.23)$ & $1.02(2.11)$ & $0.99(2.14)$ & $0.95(2.09)$ & $0.84(1.76)$ & $0.72(1.66)$ \\
\hline \multicolumn{7}{|l|}{ Dropout } \\
\hline Yes & $1.15(2.27)$ & $1.06(2.25)$ & $0.95(2.01)$ & $1.12(2.40)$ & $1.80(3.20)$ & n.a. \\
\hline No & $0.95(2.00)$ & $0.91(2.03)$ & $0.88(1.96)$ & $0.84(1.93)$ & $0.79(1.88)$ & $0.77(1.93)$ \\
\hline \multicolumn{7}{|c|}{ Dust exposure* (tertiles) } \\
\hline First & $0.82(1.72)$ & $0.78(1.80)$ & $0.80(1.79)$ & $0.74(1.73)$ & $0.77(1.93)$ & $0.85(2.03)$ \\
\hline Second & $1.06(2.24)$ & $1.03(2.12)$ & $0.94(2.04)$ & $0.98(2.18)$ & $0.82(1.77)$ & $0.73(1.68)$ \\
\hline Third & $1.05(2.13)$ & $0.99(2.24)$ & $0.91(2.04)$ & $0.84(1.91)$ & $0.80(1.94)$ & $0.69(1.80)$ \\
\hline \multicolumn{7}{|l|}{ Previous exposure } \\
\hline Yes & $1.10(2.26)$ & $1.05(2.28)$ & $0.96(2.11)$ & $0.93(2.13)$ & $0.86(2.01)$ & $0.79(1.91)$ \\
\hline No & $0.72(1.51)$ & $0.66(1.49)$ & $0.72(1.57)$ & $0.65(1.44)$ & $0.62(1.49)$ & $0.66(1.61)$ \\
\hline
\end{tabular}

n.a not available. $*$ See Table 2

The results from the cross-sectional analyses are shown in Table 5, columns 2-3. After adjustment for overdispersion, the scaled Pearson $\chi(d f=2,874)^{2}$ decreased from 1.825 to 1.000 , indicating that the model accounted adequately for the overdispersion problem. No interaction between smoking and job classification was found. Overall, the multivariable analyses attenuated the association between symptom score and job group and increased the association with smoking, as the crude symptom-score ratio was 1.77 in line operators compared with nonexposed employees, i.e., line operators had $77 \%$ more symptoms than non-exposed subjects. Similarly, the crude 
Table 5 Symptom-score ratio (SSR) with 95\% confidence intervals (95\% CI) at baseline and during the follow-up by relevant covariates using multivariate Poisson regression

\begin{tabular}{|c|c|c|c|c|c|c|}
\hline & \multicolumn{6}{|c|}{ Longitudinal analyses (follow-up) } \\
\hline & \multicolumn{2}{|c|}{ Cross-sectional (baseline) } & \multicolumn{2}{|c|}{ Dropouts } & \multicolumn{2}{|c|}{ Non-dropouts } \\
\hline & SSR & $95 \% \mathrm{CI}$ & SSR & $95 \% \mathrm{CI}$ & SSR & $95 \% \mathrm{CI}$ \\
\hline Follow-up time (years) & - & - & 0.95 & $0.88-1.01$ & 0.95 & $0.93-0.96$ \\
\hline \multicolumn{7}{|l|}{ Job categories } \\
\hline Unexposed & 1 & & 1 & & 1 & \\
\hline Non-line operators & 1.35 & $1.10-1.66$ & 1.39 & $1.09-1.77$ & 1.12 & $1.00-1.26$ \\
\hline Line operators & 1.45 & $1.18-1.78$ & 1.61 & $1.27-2.05$ & 1.13 & $1.01-1.27$ \\
\hline \multicolumn{7}{|l|}{ Gender } \\
\hline Male & 1 & & 1 & & 1 & \\
\hline Female & 0.82 & $0.67-1.00$ & 0.91 & $0.73-1.14$ & 0.73 & $0.65-0.82$ \\
\hline Familial asthma: yes versus no & 1.39 & $1.24-1.55$ & 1.42 & $1.23-1.65$ & 1.33 & $1.24-1.42$ \\
\hline DD asthma: yes versus no & 1.76 & $1.52-2.03$ & 1.54 & $1.27-1.88$ & 1.58 & $1.44-1.73$ \\
\hline Allergy: yes versus no & 1.39 & $1.23-1.57$ & 1.57 & $1.35-1.83$ & 1.28 & $1.19-1.38$ \\
\hline \multicolumn{7}{|l|}{ Age (years) } \\
\hline $20-34$ & 1 & & 1 & & 1 & \\
\hline $35-44$ & 1.17 & $1.03-1.33$ & 1.34 & $1.13-1.60$ & 1.16 & $1.07-1.26$ \\
\hline $45+$ & 1.31 & $1.14-1.50$ & 1.57 & $1.31-1.87$ & 1.26 & $1.16-1.37$ \\
\hline \multicolumn{7}{|l|}{ Smoking } \\
\hline Never smoker & 1 & & 1 & & 1 & \\
\hline Former smoker & 1.09 & $0.91-1.29$ & 1.13 & $0.88-1.45$ & 1.12 & $1.02-1.24$ \\
\hline \multicolumn{7}{|l|}{ Current (cig/day) } \\
\hline $1-9$ & 1.61 & $1.38-1.89$ & 1.90 & $1.53-2.35$ & 1.81 & $1.65-1.99$ \\
\hline $10-19$ & 2.23 & $1.94-2.57$ & 2.93 & $2.43-3.54$ & 2.55 & $2.34-2.78$ \\
\hline $20+$ & 3.27 & $2.63-4.07$ & 3.94 & $2.98-5.21$ & 3.46 & $3.04-3.92$ \\
\hline \multicolumn{7}{|l|}{ Previous exposure } \\
\hline No & 1 & & 1 & & 1 & \\
\hline Yes & 1.22 & $1.06-1.42$ & 1.14 & $0.94-1.38$ & 1.21 & $1.11-1.33$ \\
\hline
\end{tabular}

DD asthma doctor diagnosed asthma. All variables are mutually adjusted

symptom-score ratio in subjects smoking 20 cigarettes or more per day was 3.27 (not shown in table), compared with never-smokers.

In the longitudinal analyses, we found a significant interaction between dropouts and exposure status $(p=0.01)$, (not shown in table), i.e., symptom-score ratio between line operators and non-exposed employees was significantly higher in dropouts than non-dropouts. The variance of the Pearson residual was 0.998 (not shown in table), indicating that the model fitted well to the data. Thus, the longitudinal analyses were performed separately in dropouts and non-dropouts. The results of these analyses are shown in Table 5. Generally, the associations between symptom score and covariates did not vary notably between these two models and the cross-sectional results, except that the association between job classification and symptom score was markedly higher in dropouts than in non-dropouts. Among non-dropouts, the symptom-score ratio was, however, significantly higher in non-line operators and line operators compared with non-exposed employees ( $p=0.04$ for both), although the symptom score was only negligibly higher in the former groups compared with non-exposed subjects. When we analysed the data longitudinally, omitting the interaction term and dropout variable, the symptom-score ratio was $1.21(95 \%$ CI: 1.08-1.34) and $1.16(1.05-1.29)$ in line operators and non-line operators compared with non-exposed employees, respectively.

The association between symptom score and dust exposure is shown in Tables 5 and 6. In dropouts, a positive association between symptom score and dust exposure was found, $(p$-trend $=0.02)$. In non-dropouts, no association between symptom score and dust exposure was found $(p$-trend $=0.48)$. 
Table 6 Symptom-score ratio at baseline and during the follow-up in dropouts and non-dropouts by tertiles of dust exposure using the same covariates as in Table 5

\begin{tabular}{|c|c|c|c|c|c|c|}
\hline \multirow{2}{*}{$\begin{array}{l}\text { Tertiles* of dust } \\
\text { exposure }\end{array}$} & \multicolumn{2}{|c|}{ Baseline } & \multicolumn{2}{|c|}{ Dropouts } & \multicolumn{2}{|c|}{ Non-dropouts } \\
\hline & SSR & $95 \% \mathrm{CI}$ & SSR & $95 \% \mathrm{CI}$ & SSR & $95 \% \mathrm{CI}$ \\
\hline First & 1 & & 1 & & 1 & \\
\hline Second & 1.12 & $0.98-1.28$ & 1.28 & $1.05-1.55$ & 1.04 & $0.96-1.12$ \\
\hline Third & 1.11 & $0.97-1.28$ & 1.37 & $1.13-1.66$ & 1.04 & $0.95-1.14$ \\
\hline
\end{tabular}

* See Table 2

\section{Discussion}

In this study, we have found a strong association between respiratory symptoms and exposure in employees who left the study. The association between symptoms and exposure was markedly weaker in non-dropouts, although still significant.

The strength of this study was the longitudinal design, using repeated measurements of symptoms, as well as exposure and other covariates. Interestingly, a convincing association between symptoms and the exposure indices were found only in those who left the study, whereas the symptom score was negligibly higher among exposed than non-exposed employees among those who completed the follow-up. These findings are compatible with a healthy worker effect (Radon et al. 2002). Nonetheless, we have previously found that line operators and non-line operators had significantly lower dropout rates than nonexposed individuals (Fitzmaurice 2004). The latter relation can occur because non-exposed employees were lost from follow-up due to other reasons, e.g., lower motivation to meet at repeated health examinations. Surprisingly, the symptom-score ratio between line operators or nonline operators and non-exposed employees was only marginally lower in the cross-sectional analyses of the baseline data, compared with symptom-score ratio between the corresponding groups among dropouts in the longitudinal analyses. This result indicates that crosssectional studies do not necessarily underestimate the association between effect and exposure markedly. Moreover, when we ignored the interaction term and the dropout variable, the symptom-score ratio between line operators or non-line operators and non-exposed subjects during the follow-up was considerably lower than the corresponding ratios at baseline. However, the longitudinal attenuation of the association may be due to confounding by selective dropout rate during the follow-up, as the dropout rate declined rapidly during the first three examinations. A similar effect was also found in grain workers followed over 15 years (Voll-Aanerud et al. 2008). In the latter study, the decrease in the prevalence of symptoms was associated with a decrease in grain exposure.

Except from symptoms of chronic bronchitis, the prevalence of each symptom was almost unrelated to symptom score, indicating that each of the remaining symptoms is almost interchangeable. Actually, the association between each symptom and mortality in a general population did not vary much between different symptoms (Frostad et al. 2006a). Nonetheless, a strong association between increasing symptom score and mortality was found. Moreover, symptom score is related to disease severity and healthrelated quality of life (Leidy et al. 2003; Voll-Aanerud et al. 2008). Thus, we believe that it was well-justified to focus on symptom score instead of individual symptoms in this study. Furthermore, this choice simplifies the analytical approach to the data.

The association between the prevalence of chronic bronchitis and symptom score deserves some attention. The prevalence of chronic bronchitis increases, as the number of other symptoms increased, i.e., in the most severe cases. Thus, it appears that chronic bronchitis is an indication of more severe disorder than the other symptoms.

To the best of our knowledge, this is the first longitudinal study of the association between respiratory symptoms and occupational exposure in the smelting industry. Previously we found that subjects reporting respiratory symptoms were more likely to dropout from the study, and probably from the industry, than asymptomatic employees (Soyseth et al. 2008). In this study, we have found a positive association between occupational exposure and respiratory symptoms in the dropouts, whereas the association between exposure and respiratory symptoms was considerably weaker among those who continued their exposure than among dropouts.

The choice of exposure index could also be discussed. In this report, we have used both a qualitative classification index (line, non-line operators and non-exposed employees) as well as an estimate of dust exposure based on a JEM (Foreland et al. 2008; Johnsen et al. 2010). The latter exposure classification enables quantification of the outcome (symptom score) to the level of dust exposure. However, using a JEM, some misclassification of exposure among the employees is likely to occur (Checkoway et al. 2004). Such misclassification is likely to be non-differential and distorts the association between exposure and outcome towards the null-effect (Blair et al. 2007; Goldberg et al. 1993). Thus, a positive association between symptom score and dust exposure in non-dropouts cannot be excluded.

The limitation of the study is that we did not record data at the time the participants left the study and that we did not know the reason for leaving the study. Misclassification of any covariate such as dropout will reduce the specificity 
of this covariate, and thereby dilute the association with symptom score. We could not differentiate between those who only left the study from those who left the industry. It is likely, however, that lack of such information dilutes the association between symptoms and exposure among the dropouts.

In conclusion, subjects having respiratory symptoms that are associated with occupational dust exposure are more prone to leave their jobs than individuals who do not have work-related airways symptoms.

Acknowledgments The authors thank the smelting industry, both the management and the employees, for their considerable cooperation. We are grateful to the local occupational health services that performed the examinations of the employees. We also thank the advisory council; Digernes V (PhD), Efskind J (MD), Erikson B (MSc), Astrup EG $(\mathrm{PhD})$ and Kjuus $\mathrm{H}(\mathrm{PhD})$ for their valuable comments on the manuscript. Especially, we want to thank to Astrup EG for her help with the job classification. The study was accomplished with valuable support from the Federation of Norwegian Industries.

Conflict of interest The study was funded by the Confederation of Norwegian Business and Industry (CNBI) Working Environment Fund and the Norwegian smelting industry.

Open Access This article is distributed under the terms of the Creative Commons Attribution Noncommercial License which permits any noncommercial use, distribution, and reproduction in any medium, provided the original author(s) and source are credited.

\section{References}

Blair A et al (2007) Methodological issues regarding confounding and exposure misclassification in epidemiological studies of occupational exposures. Am J Ind Med 50(3):199-207

Checkoway H, Pearce N, Kriebel D (2004) Research methods in occupational epidemiology, vol XIV. Oxford University Press, Oxford, p 372

Fitzmaurice GM (2004) Applied longitudinal analysis. Wiley-Interscience, Hoboken, vol XIX, p 506

Foreland S et al (2008) Exposure to fibres, crystalline silica, silicon carbide and sulphur dioxide in the Norwegian silicon carbide industry. Ann Occup Hyg 52(5):317-336

Frostad A et al (2006a) Respiratory symptoms as predictors of allcause mortality in an urban community: a 30-year follow-up. J Intern Med 259(5):520-529

Frostad A et al (2006b) Respiratory symptoms and 30 year mortality from obstructive lung disease and pneumonia. Thorax 61(11): 951-956
Frostad A et al (2007) Respiratory symptoms and long-term cardiovascular mortality. Respir Med 101(11):2289-2296

Goldberg $\mathrm{M}$ et al (1993) Job exposure matrices in industry. Int J Epidemiol 22(Suppl 2):S10-S15

Johnsen HL et al (2008a) Quantitative and qualitative assessment of exposure among employees in Norwegian smelters. Ann Occup Hyg 52(7):623-633

Johnsen HL et al (2008b) Decreased lung function among employees at Norwegian smelters. Am J Ind Med 51(4):296-306

Johnsen HL et al (2008c) Production of silicon alloys is associated with respiratory symptoms among employees in Norwegian smelters. Int Arch Occup Environ Health 81(4):451-459

Johnsen HL et al (2010) Dust exposure assessed by a job exposure matrix is associated with increased annual decline of FEV1 a five-year prospective study of employees in Norwegian smelters. Am J Respir Crit Care Med 181(11):1234-1240

Kongerud J, Vale JR, Aalen OO (1989) Questionnaire reliability and validity for aluminum potroom workers. Scand J Work Environ Health 15(5):364-370

Krzyzanowski M, Wysocki M (1986) The relation of thirteen-year mortality to ventilatory impairment and other respiratory symptoms: the Cracow study. Int J Epidemiol 15(1):56-64

Lange P et al (1990) Relation of ventilatory impairment and of chronic mucus hypersecretion to mortality from obstructive lung disease and from all causes. Thorax 45(8):579-585

Leidy NK et al (2003) Evaluating symptoms in chronic obstructive pulmonary disease: validation of the breathlessness, cough and sputum scale. Respir Med 97(Suppl A):S59-S70

Radon K, Goldberg M, Becklake M (2002) Healthy worker effect in cohort studies on chronic bronchitis. Scand J Work Environ Health 28(5):328-332

Rosengren A, Wilhelmsen L (1998) Respiratory symptoms and longterm risk of death from cardiovascular disease, cancer and other causes in Swedish men. Int J Epidemiol 27(6):962-969

SAS Institute Inc. (2004) SAS OnlineDoc ${ }^{\circledR}$ 9.1.3. SAS Institute Inc, Cary, NC

Soyseth V et al (2007) Production of silicon metal and alloys is associated with accelerated decline in lung function: a 5-year prospective study among 3924 employees in Norwegian smelters. J Occup Environ Med 49(9):1020-1026

Soyseth V, Johnsen HL, Kongerud J (2008) Prediction of dropout from respiratory symptoms and airflow limitation in a longitudinal respiratory study. Scand J Work Environ Health 34(3): 224-229

Soyseth V et al (2011) Prevalence of airflow limitation among employees in Norwegian smelters: a longitudinal study. Occup Environ Med 68(1):24-29

Vestbo J, Knudsen KM, Rasmussen FV (1989) The value of mucus hypersecretion as a predictor of mortality and hospitalization. An 11-year register based follow-up study of a random population sample of 876 men. Respir Med 83(3):207-211

Voll-Aanerud M et al (2008) Respiratory symptoms, COPD severity, and health related quality of life in a general population sample. Respir Med 102(3):399-406 